\title{
Photosynthetic energy conversion under extreme conditions-I: important role of lipids as structural modulators and energy sink under $N$-limited growth in Antarctic sea ice diatoms
}

\author{
Thomas Mock ${ }^{\mathrm{a}, *}$, Bernd M.A. Kroon ${ }^{\mathrm{a}, \mathrm{b}}$ \\ a Alfred-Wegener-Institute for Polar and Marine Research, Am Handelshafen 12, D-27570 Bremerhaven, Germany \\ ${ }^{\mathrm{b}}$ KroonAqa GmbH, Kurrhahnstraße 9, D-27572 Bremerhaven, Germany
}

Received 14 December 2001; received in revised form 2 May 2002

\begin{abstract}
The availability of dissolved nutrients such as nitrate under extreme low temperatures is a strong determinant in the development and growth of ice diatoms. Consequently we investigated regulation of photosynthesis in a mixed culture of three diatom species, which grew in chemostats at $-1{ }^{\circ} \mathrm{C}, 15 \mu \mathrm{mol}$ photons $\mathrm{m}^{-2} \mathrm{~s}^{-1}$ under $N$-limitation. When nitrogen is limiting, pigment-protein complexes are one of the most affected structures under low-light conditions. The loss of integral polar thylakoid components destabilized the bilayer structure of the membrane with consequences for lipid composition and the degree of fatty acid desaturation. $N$-Limitation caused a decrease in monogalactosydiacylglycerol (MGDG) and a simultaneous increase in bilayer forming digalactosyldiacylglycerol (DGDG). Their ratio MGDG:DGDG decreased from 3.4 \pm 0.1 to $1.1 \pm 0.4$, while 20:5 n-3 fatty acids of chloroplast related phospholipid classes such as phosphatidylglycerol (PG) increased under $N$-limitation. These data reveal that lipids are important components, required to sustain membrane structure under a deficiency of integral membrane bound proteins and pigments. Nonetheless, energy conversion at photosystem II is still affected by $N$-limitation despite this structural regulation. Photosynthetic quantum yield $\left(F_{\mathrm{v}} / F_{\mathrm{m}}\right)$ and electron transport rates decreased under $N$-limitation caused by an increasing amount of electron acceptors (second stable electron acceptor $=\mathrm{Q}_{\mathrm{B}}$ ) which had slower reoxidation kinetics. The energy surplus under these conditions is stored in triacylglycerols, the main energy sink in Antarctic sea ice diatoms under $N$-limitation. (C) 2002 Elsevier Science Ltd. All rights reserved.
\end{abstract}

Keywords: Bacillariophyceae; Carbohydrates; Fatty acids; Fluorescence; Lipids; Low temperature; Nitrogen limitation; Pigments; Proteins; Sea ice

\section{Introduction}

A dominant feature of the Southern Ocean is the sea ice canopy, which has been recognized as an important habitat that significantly contributes to Southern Ocean productivity (Arrigo et al., 1997). Productivity in sea ice is mainly based on micro-organisms, living in a network of brine channels and pockets, which have an average diameter of $200 \mu \mathrm{m}$ (Weissenberger et al., 1992). This narrow space is characterized by low temperature, low photon flux densities and a reduced resupply of nutrients from seawater (e.g. Eicken, 1992; McMinn et al., 1999). Sea ice is therefore an environment, where

* Corresponding author. Tel.: +49-471-4831-1893; fax: +49-4714831-425.

E-mail address: tmock@awi-bremerhaven.de (T. Mock). organisms are always colimited by more than one resource and temperature, which allows the coexistance of species (Hutchinson, 1961).

Studies with green algae and higher plants have shown that cold adapted enzymes and an increase in membrane fluidity are important prerequisites for optimal photosynthesis and growth under polar conditions (Thomashow, 1998; Routaboul et al., 2000; Allen and Ort, 2001). Obviously only those diatom species can probably persist in Antarctic sea ice, which are cold adapted and able to regulate photosynthesis efficiently under simultaneous light and $N$-limitation. Ecophysiological investigations based on both limitations are still rare for sea ice diatoms and have been either conducted with natural communities or with single species (Tillmann et al., 1989; Kirst and Wiencke, 1995; Taguchi and Smith, 1997; McMinn et al., 1999). Our approach 


\begin{tabular}{|c|c|c|c|}
\hline \multicolumn{2}{|c|}{ Nomenclature } & \multirow{2}{*}{$\begin{array}{l}P \text { vs } I \\
\alpha\end{array}$} & \multirow{3}{*}{$\begin{array}{l}\text { saturation flashes at a rate of } K_{C} \\
\text { photosynthesis }(P) \text { versus irradiance }(I) \\
\text { light limited slope of the } P \text { vs } I \text { curve/ } \\
\text { light utilization effiziency }\end{array}$} \\
\hline $\mathrm{RC}$ & reaction centre & & \\
\hline PS II, I & photosystem II, I & & \\
\hline LHC & light harvesting complex & $\mathrm{Ik}$ & light level at which photosynthesis \\
\hline $\mathrm{D} 1 / \mathrm{D} 2$ & PS II reaction centre proteins & & saturates \\
\hline $\mathrm{Q}_{\mathrm{A}}$ & $\begin{array}{l}\text { quinone A, first stable electron acceptor } \\
\text { of PS II }\end{array}$ & $\begin{array}{l}P_{\max } \\
K\end{array}$ & $\begin{array}{l}\text { mximum rate of photosynthesis } \\
\text { rate constant for fluorescence decay }\end{array}$ \\
\hline $\mathrm{Q}_{\mathrm{B}}$ & quinone $\mathrm{B}$, second stable electron & & measurements \\
\hline$F$ & $\begin{array}{l}\text { acceptor } \\
\text { fluorescence. Subscripts } \mathbf{o}, \mathbf{v}, \mathbf{m} \text { repre- }\end{array}$ & $A, B, C_{\text {comp }}$ & $\begin{array}{l}\text { amplitudes of fluorescence decay rate } \\
\text { constants }(K)\end{array}$ \\
\hline & & $J_{\text {con }}$ & $\begin{array}{l}\text { connectivity between reaction centres } \\
\text { (PS II) }\end{array}$ \\
\hline & maximum levels, respectively. & FA & fatty acid \\
\hline$F_{v} / F_{m}$ & quantum yield & PUFA & polyunsaturated fatty acid \\
\hline$q$ & reaction centers & MGDG & monogalactosyldiacylglycerol \\
\hline$p$ & connectivity between PS II units & DGDG & digalactosyldiacylglycerol \\
\hline$\Phi_{\mathrm{f}}$ & fluorescence yield & $\mathrm{PC}$ & phosphatidylcholine \\
\hline$\Phi_{\mathrm{P}}$ & quantum yield & PG & phosphatidylglycerol \\
\hline$q 1$ & open reaction centres & $\mathrm{PE}$ & phosphatidylethanolamin \\
\hline$q 0$ & closed reaction centres & PI & phosphatidylinositol \\
\hline$\sigma$ & effective cross section of PS II & TAG & triacylglycerol \\
\hline$A$ & $\begin{array}{l}\text { fraction of PS II characterized by a fast } \\
\text { fluorescence decay after turnover } \\
\text { saturation flashes at a rate of } K_{A}\end{array}$ & $\begin{array}{l}\text { SQDG } \\
\text { NADPH }\end{array}$ & $\begin{array}{l}\text { sulfoquinovosyldiacylglycerol } \\
\text { nicotinamide-adenine-dinucleotide- } \\
\text { phosphate }\end{array}$ \\
\hline$B$ & fraction of PS II characterized by a & ATP & adenosine-tri-phosphate \\
\hline & middle fluorescence decay after turn- & POC & particulate organic carbon \\
\hline & over saturation flashes at a rate of $K_{B}$ & PON & particulate organic nitrogen \\
\hline$C$ & $\begin{array}{l}\text { craction of PS II characterized by a } \\
\text { slow fluorescence decay after turnover }\end{array}$ & DIN & dissolved inorganic nitrogen \\
\hline
\end{tabular}

studies the mechanisms of photosynthesis regulation in diatom species, which coexist in the natural sea ice community (Fragilariopsis curta, Navicula gelida var. antarctica, Nitzschia medioconstricta) observed during an Antarctic expedition ("Polarstern" ANT XVI). We assume, that these diatoms share similar regulation mechanisms that are responsible for their success. Consequently, we investigated regulation of photosynthesis in a mixed culture of these three diatom species, which grew in chemostats at $-1{ }^{\circ} \mathrm{C}$ under $N$-limitation. Defined conditions and the restricted number of diatom species in one chemostat enabled us to investigate processes of regulation, which might be universal for this group of diatoms. One of these fundamental processes is the regulation of photosynthetic energy conversion by chloroplast lipids, an unknown process in Antarctic sea ice diatoms. It has been pointed out that the degree of fatty acid desaturation and the lipid composition in thylakoide membranes is critical in maintaining optimal photosynthesis (Siegenthaler and Murata, 1998). This study focusses on nitrogen stress and its consequences for energy conversion at photosystem II (PS II) and the associated lipid classes as well as the desaturation of their fatty acids. Additionally, we present a concept of lipids as structural modulators and energy sink in $N$-limited Antarctic sea ice diatoms.

\section{Results}

\subsection{Physiology}

PS II related parameters of continuous cultures were significantly influenced by nitrogen availability (Table 1). Under nitrogen deplete conditions, during a $50 \%$ reduction in growth rate $\left(0.28\right.$ day $\left.^{-1}\right), F_{\mathrm{v}} / F_{\mathrm{m}}$ decreases by $30 \%$ whereas connectivity between reaction centres decreased by at least $10 \%$. Reoxidation kinetics of $\mathrm{Q}_{\mathrm{A}}$ (first stable electron acceptor) were also negatively influenced by $N$-limitation for all three processes (Table 1). The electron transport is slower under $N$-limitation although more $\mathrm{Q}_{\mathrm{B}}$ (second stable electron acceptor) was bound at D1 (reaction center protein of PS II), which is indicated by the fluorescent amplitude A ( $A_{\text {comp }}$ ) (Table 2). This amount of bound $\mathrm{Q}_{\mathrm{B}}$ was not influenced by 30 min dark adaptation of samples, which 
was revealed in the comparison to measurements made only $90 \mathrm{~s}$ after sampling. Nevertheless, the rate constants remained high in comparison to other algae (Kroon 1994; Kroon and Prezelin, 1995).

Photosynthesis $(P)$ defined as $F_{\mathrm{v}} / F_{\mathrm{m}}$ *photon flux density (PFD) vs irradiance $(I)$ measurements revealed that $P_{\max }$ (maximum of $P$ ), Ik (irradiance where $P$ saturates) as well as $\alpha$ (light utilization efficiency defined as the slope of the $P$ vs $I$ curve) were negatively effected by $N$-limitation (Fig. 1 ). Each of these parameters was calculated on the basis of quantum yield $\left(F_{\mathrm{v}} / F_{\mathrm{m}}\right)$ measurements, which were generally higher under nitrogen replete conditions (Fig. 2). This is primarily caused by a higher amount of oxidized reaction centres $\left(K_{\text {open }}\right)$. Nitrogen limitation resulted in a stronger reduction of reaction centres because of reduced availability of nitrate as a very important electron sink. Consequently, the electrons can not be efficiently used for the reduction of nitrate and thus accumulate within the plastoquinone pool (PQ).

Pigment concentrations were affected by $N$-limitation. Chlorophyll (Chl) $c, a$ and fucoxanthin decreased by about 50\% (Fig. 3) with simultaneous changes in their

Table 1

Fluorescence variables for dissolved inorganic nitrogen (DIN) replete growth $\left(0.55 \mathrm{day}^{-1}\right)$ and deplete growth $\left(0.28 \mathrm{day}^{-1}\right)$

\begin{tabular}{lcc}
\hline Variable & DIN replete & DIN deplete \\
\hline$J_{\text {con }}$ & $0.341 \pm 0.010$ & $0.308 \pm 0.017$ \\
$K_{\text {open }}$ & $0.408 \pm 0.015$ & $0.255 \pm 0.021$ \\
$F_{\mathrm{v}} / F_{\mathrm{m}}($ yield $)$ & $0.337 \pm 0.009$ & $0.236 \pm 0.025$ \\
$K_{\mathrm{A}}\left(\mathrm{m} \mathrm{s}^{-1}\right)$ & $11.16 \pm 1.34$ & $4.24 \pm 1.01$ \\
$K_{\mathrm{B}}\left(\mathrm{m} \mathrm{s}^{-1}\right)$ & $0.42 \pm 0.12$ & $0.16 \pm 0.08$ \\
$K_{\mathrm{C}}\left(\mathrm{m} \mathrm{s}^{-1}\right)$ & $0.02 \pm 0.02$ & $0.00 \pm 0.01$ \\
$r^{2}(n=5)$ & 0.966 & 0.797
\end{tabular}

Connectivity $\left(J_{\text {con }}\right)$ between reaction centres $(\mathrm{RC})$, open $\left(K_{\text {open }}\right) \mathrm{RC}$ and quantum yield are based on DCMU induction measurements. Fluorescence decay rate constants for fast $K_{A}$, middle $K_{B}$ and slow $K_{C}$ component. Values are given as relative units; $n=5 ; r^{2}=$ model fit.

Table 2

Amplitudes of fluorescence decay rate constants for fast $K_{A}\left(A_{\text {comp }}\right)$, middle $K_{B}\left(B_{\text {comp }}\right)$ and slow $K_{C}\left(C_{\text {comp }}\right)$ component for dissolved inorganic nitrogen (DIN) replete growth $\left(0.55 \mathrm{day}^{-1}\right)$ and deplete growth $\left(0.28 \text { day }^{-1}\right)^{\mathrm{a}}$

\begin{tabular}{llllll}
\hline Variable & \multicolumn{2}{l}{ DIN replete } & & \multicolumn{2}{l}{ DIN deplete } \\
\cline { 2 - 3 } \cline { 5 - 6 } & $90 \mathrm{~s}$ & $30 \mathrm{~min}$ & & $90 \mathrm{~s}$ & $30 \mathrm{~min}$ \\
\hline$A_{\text {comp }}$ & 0.011 & 0.012 & & 0.018 & 0.017 \\
& 0.012 & 0.012 & & 0.022 & 0.018 \\
$B_{\text {comp }}$ & 0.006 & 0.004 & & 0.027 & 0.024 \\
& 0.010 & 0.006 & & 0.025 & 0.025 \\
$C_{\text {comp }}$ & 0.001 & 0.001 & 0.002 & 0.006 \\
& 0.001 & 0.001 & 0.009 & 0.002 \\
\hline
\end{tabular}

a They were determined $90 \mathrm{~s}$ and 30 min after sampling; $n=2$.

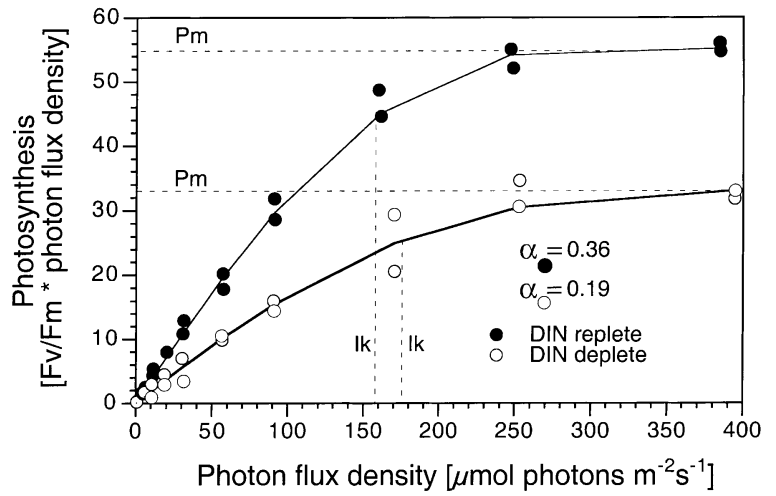

Fig. 1. Photosynthesis as $F_{\mathrm{v}} / F_{\mathrm{m}}{ }^{*}$ photon flux density vs irradiance in ice diatoms under dissolved inorganic nitrogen (DIN) replete $(\mu=0.55$ day $\left.^{-1}\right)$ and DIN deplete conditions $\left(\mu=0.28\right.$ day $\left.^{-1}\right)$ are based on DCMU induction measurements. Photosynthetic parameters $\alpha$ (light utilization effiziency), Ik (quantum flux of PAR at onset of light saturation), $P_{\max }$ (maximum photosynthetic rate) were calculated after Eilers and Peeters (1988); $n=2$.

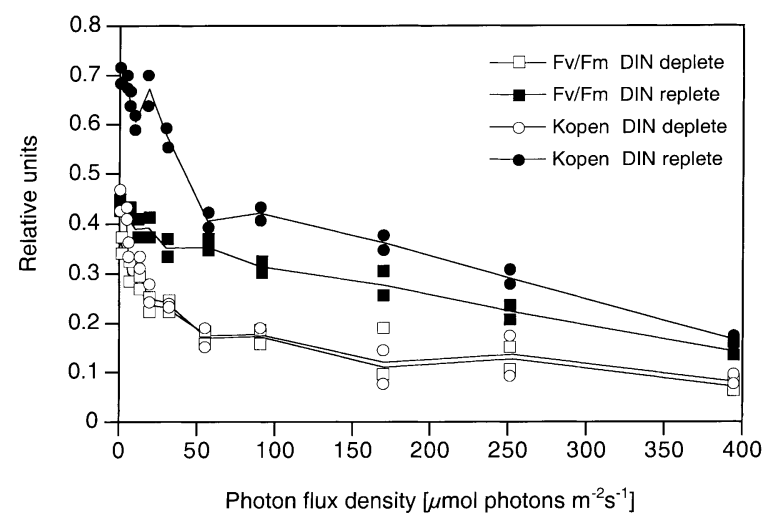

Fig. 2. Photophysiological parameters of photosynthesis vs irradiance curves based on DCMU induction measurements under dissolved inorganic nitrogen (DIN) replete $\left(\mu=0.55 \mathrm{day}^{-1}\right)$ and DIN deplete $\left(\mu=0.28\right.$ day $\left.^{-1}\right)$ conditions. Kopen $=$ relative proportion of oxidized reaction centres; $F_{\mathrm{v}} / F_{\mathrm{m}}=$ quantum yield of photosynthesis; $n=2$.

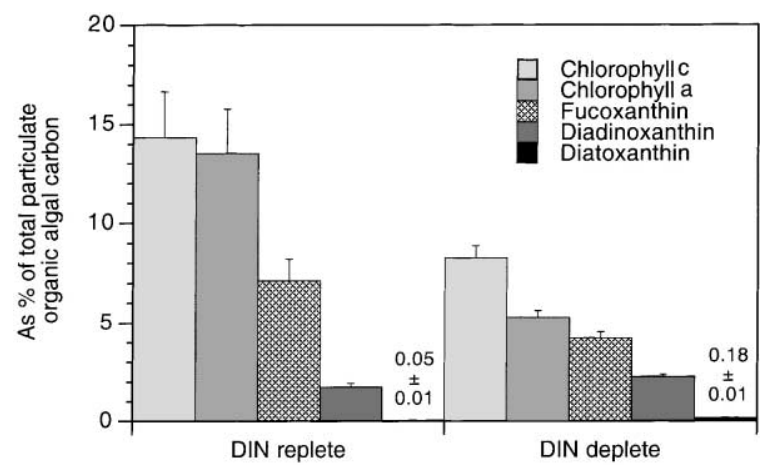

Fig. 3. Pigment composition of sea ice diatoms as $\%$ of total particulate organic algal carbon under dissolved inorganic nitrogen (DIN) replete and DIN deplete conditions with corresponding growth rates of 0.55 and $0.28 \mathrm{day}^{-1}$, respectively. Carotene was always below detection limit. Error bars denote standard deviations; $n=3$. 
relative ratios, chl $c: a$ from 1.0 to 1.6 , and fucoxanthin:chl $a$ from 0.5 to 0.8 . Other carotenoids (diadinoxanthin, diatoxanthin) increased slightly, whereas $\beta$-carotene was always below the detection limit.

\subsection{Biochemistry}

$N$-Limitation imposed a potential problem for the algae: The protein pathway is partially blocked by a lack of sufficient dissolved nitrogen relative to the light input. Thus, the biochemical composition of the cell changed dramatically, which is already known from many other investigations (e.g. Pohl and Zurheide, 1979; Shifrin and Chisholm, 1981). The most frequently observed phenomenon under $N$-limitation is a proportional reduction of intracellular proteins to the reduced external availability of dissolved inorganic nitrogen (Fig. 4). Consequently the energy surplus from photosynthesis is stored or exudated in form of reduced substances, which contain no or only less nitrogen as in carbohydrates and lipids. Sea ice diatoms are known to store energy in the form of lipids, which was confirmed in our experiment. Lipids increased dramatically during $N$-limitation (Fig. 4). This was mainly caused by triacylglycerol production but also by production of polar lipids constituting diverse kinds of membranes (Fig. 5). The well known glycolipids, monogalactosyldiacylglycerol (MGDG) and digalactosyldiacylglycerol (DGDG), which are exclusively present in chloroplasts, were the dominant polar lipid classes in sea ice diatoms (Fig. 6). Their ratios changed during nitrate limitation due to a decrease in MGDG and an increase in DGDG (Fig. 7). Phospholipids phosphatidylcholine (PC), phosphatidylglycerol (PG) and phosphatidylinositol (PI) were preferentially synthesized during nitrogen limitation, whereas phosphatidylethanolamin (PE) decreased. PC was more concentrated under nitrogen limited growth, despite the presence of methylated nitrogen in the molecule, which probably indicates an

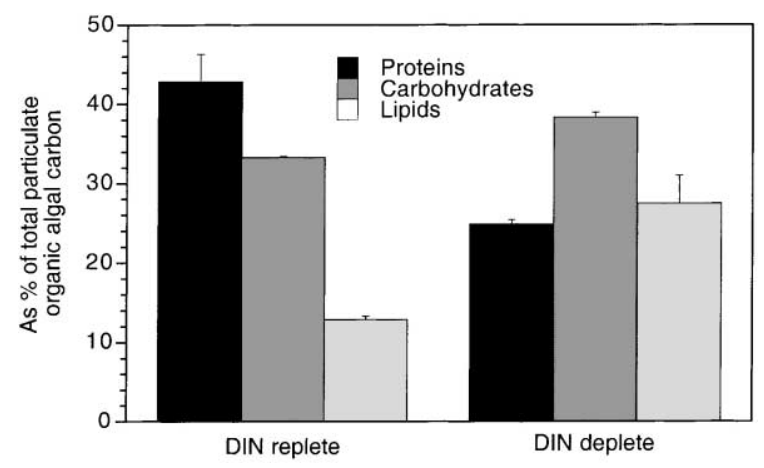

Fig. 4. Macromolecular composition of sea ice diatoms as $\%$ of total particulate organic algal carbon under dissolved inorganic nitrogen (DIN) replete and DIN deplete conditions with corresponding growth rates of 0.55 and $0.28 \mathrm{day}^{-1}$, respectively. Error bars denote standard deviations; $n=3$.

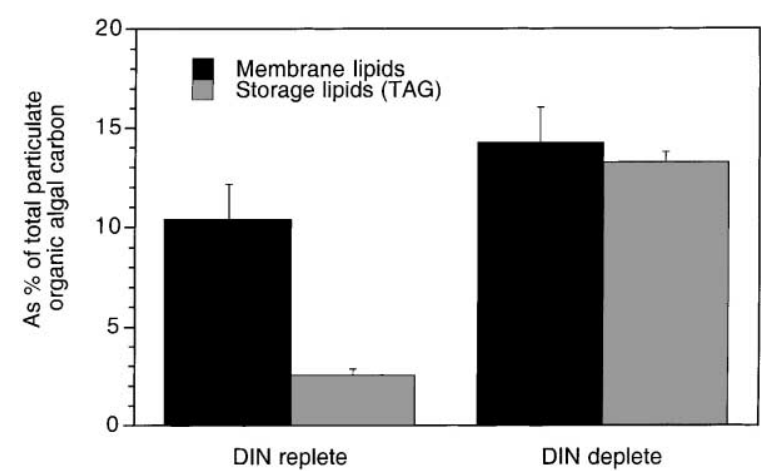

Fig. 5. Polar membrane lipids and storage lipids (triacylglycerol TAG) as $\%$ of total particulate organic algal carbon under dissolved inorganic nitrogen (DIN) replete and DIN deplete conditions with corresponding growth rates of 0.55 and $0.28 \mathrm{day}^{-1}$, respectively. Error bars denote standard deviations; $n=3$.

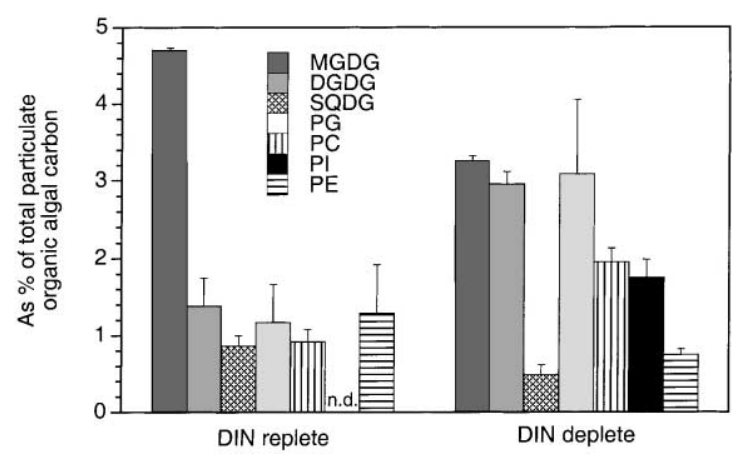

Fig. 6. Glyco- and phospholipid classes of sea ice diatoms in $\%$ of total particulate organic algal carbon under dissolved inorganic nitrogen (DIN) replete and DIN deplete conditions with corresponding growth rates of 0.55 and $0.28 \mathrm{day}^{-1}$, respectively. Error bars denote standard deviations; n.d. $=$ not detectable; $n=3$.

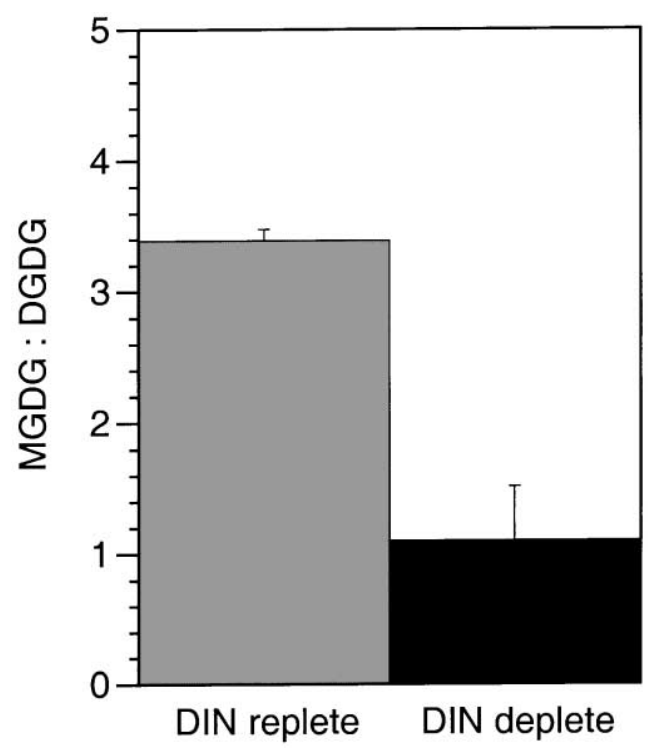

Fig. 7. Ratio of monogalactosyldiacylglycerol (MGDG) to digalactosydiacylglycerol (DGDG) under dissolved inorganic nitrogen (DIN) replete and DIN deplete conditions with corresponding growth rates of 0.55 and 0.28 day $^{-1}$, respectively. Error bars denote standard deviations; $n=3$. 

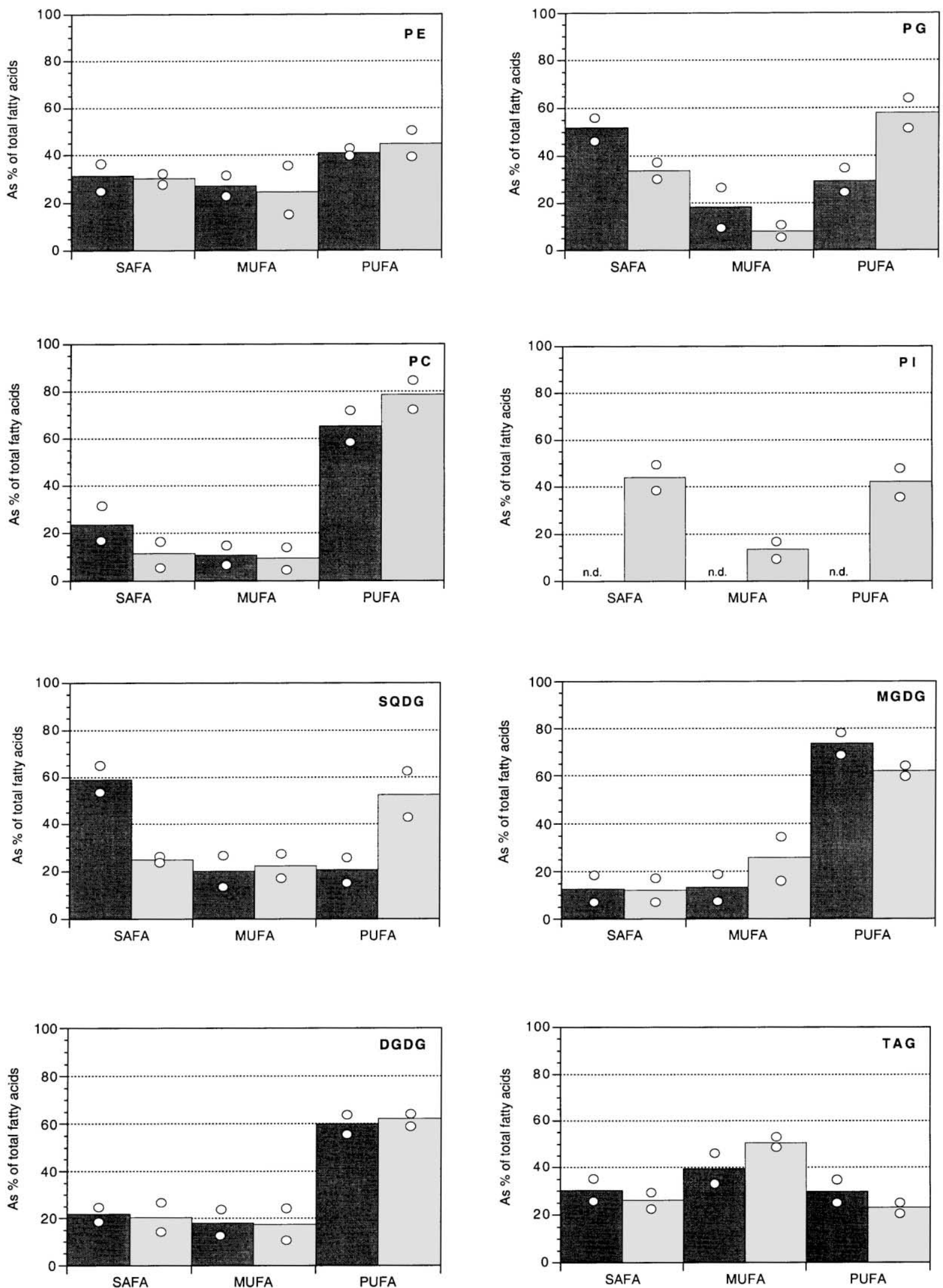

DIN replete $\square$ DIN deplete

Fig. 8. Distribution of saturated (SAFA), monounsaturated (MUFA) and polyunsaturated fatty acids (PUFA) in lipid classes of sea ice diatoms as $\%$ of total particulate organic algal carbon under dissolved inorganic nitrogen (DIN) replete and DIN deplete conditions with corresponding growth rates of 0.55 and 0.28 day $^{-1}$, respectively; n.d. $=$ not detectable; $n=2$. 
Table 3

Fatty acid composition in lipid classes of sea ice diatoms during dissolved inorganic nitrogen (DIN) replete (growth rate 0.55 day ${ }^{-1}$ ) and deplete growth (growth rate 0.28 day $^{-1}$ )

\begin{tabular}{|c|c|c|c|c|c|c|c|c|c|c|c|c|c|c|c|c|}
\hline \multirow[t]{2}{*}{ Fatty acid } & \multicolumn{2}{|l|}{$\mathrm{PC}$} & \multicolumn{2}{|l|}{ PI } & \multicolumn{2}{|l|}{$\mathrm{PE}$} & \multicolumn{2}{|l|}{ PG } & \multicolumn{2}{|l|}{ SQDG } & \multicolumn{2}{|l|}{ DGDG } & \multicolumn{2}{|c|}{ MGDG } & \multicolumn{2}{|l|}{ TAG } \\
\hline & $\begin{array}{l}\text { DIN } \\
\text { replete }\end{array}$ & $\begin{array}{l}\text { DIN } \\
\text { deplete }\end{array}$ & $\begin{array}{l}\text { DIN } \\
\text { replete }\end{array}$ & $\begin{array}{l}\text { DIN } \\
\text { deplete }\end{array}$ & $\begin{array}{l}\text { DIN } \\
\text { replete }\end{array}$ & $\begin{array}{l}\text { DIN } \\
\text { deplete }\end{array}$ & $\begin{array}{l}\text { DIN } \\
\text { replete }\end{array}$ & $\begin{array}{l}\text { DIN } \\
\text { deplete }\end{array}$ & $\begin{array}{l}\text { DIN } \\
\text { replete }\end{array}$ & $\begin{array}{l}\text { DIN } \\
\text { deplete }\end{array}$ & $\begin{array}{l}\text { DIN } \\
\text { replete }\end{array}$ & $\begin{array}{l}\text { DIN } \\
\text { deplete }\end{array}$ & $\begin{array}{l}\text { DIN } \\
\text { replete }\end{array}$ & $\begin{array}{l}\text { DIN } \\
\text { deplete }\end{array}$ & $\begin{array}{l}\text { DIN } \\
\text { replete }\end{array}$ & $\begin{array}{l}\text { DIN } \\
\text { deplete }\end{array}$ \\
\hline 14:0 & 7.46 & 4.08 & - & 8.06 & 8.40 & 6.66 & 21.37 & 5.72 & 22.80 & 5.57 & 8.17 & 10.75 & 4.66 & 5.64 & 9.65 & 6.59 \\
\hline 15:0 & - & - & - & - & 1.24 & 0.47 & - & - & - & - & - & 0.26 & 3.32 & 0.61 & 0.43 & 0.71 \\
\hline $16: 0$ & 14.12 & 7.08 & - & 36.06 & 21.02 & 23.27 & 30.60 & 28.14 & 28.58 & 17.32 & 10.81 & 9.32 & 3.50 & 5.78 & 19.34 & 18.55 \\
\hline 18:0 & 2.04 & 0.46 & - & - & 0.95 & - & - & - & 7.67 & 2.08 & 2.89 & - & 1.37 & 0.18 & 1.11 & 0.39 \\
\hline $16: 1 n-7$ & 7.30 & 4.58 & - & 13.67 & 23.53 & 23.06 & 11.88 & 8.00 & 20.21 & 15.72 & 8.45 & 11.56 & 8.72 & 16.65 & 36.02 & 45.46 \\
\hline $18: 1 n-9$ & 1.66 & 1.99 & - & - & & - & - & - & - & 2.77 & 6.37 & 1.18 & 0.96 & 3.83 & 3.02 & 4.34 \\
\hline $18: 1 n-7$ & 1.82 & 1.16 & - & - & 3.77 & 1.74 & 6.60 & - & - & 2.31 & - & - & 0.83 & 0.23 & - & 0.38 \\
\hline $20: 1 n-9$ & - & 1.83 & - & - & & - & - & - & - & 1.66 & 3.30 & 4.69 & 2.96 & 5.04 & 0.50 & 0.39 \\
\hline $16: 2 n-?$ & 2.87 & - & - & - & & - & - & - & - & - & 10.59 & 6.62 & 2.48 & 2.99 & 1.69 & 1.06 \\
\hline $16: 3 n-?$ & - & - & - & - & & - & - & - & - & - & - & 0.50 & 8.45 & 3.17 & 1.12 & 0.35 \\
\hline $16: 4 n-1$ & - & - & - & - & & - & - & - & 9.46 & 11.41 & 4.45 & 2.89 & 35.41 & 27.38 & 1.57 & 1.29 \\
\hline $18: 2 n-6$ & 5.55 & 3.45 & - & - & 0.80 & 0.64 & - & - & - & 14.17 & - & 1.04 & 1.84 & 4.02 & 2.18 & 1.44 \\
\hline $18: 3 n-3$ & 2.98 & 2.54 & - & - & & - & - & - & - & - & - & 1.10 & 2.38 & 0.50 & 0.91 & 1.50 \\
\hline $18: 4 n-3$ & 7.6 & 6.72 & - & - & & 0.81 & 6.65 & - & - & 2.06 & 11.81 & 17.78 & - & 2.76 & 6.38 & 5.97 \\
\hline $20: 2 n-?$ & - & - & - & - & 13.36 & 8.37 & - & - & - & - & - & - & - & - & 1.47 & - \\
\hline $20: 4 n-6$ & - & 0.94 & - & - & & - & - & - & - & - & - & - & - & 0.38 & - & 0.07 \\
\hline $20: 4 n-3$ & 1.62 & 1.48 & - & 23.98 & 3.20 & 2.745 & - & - & - & - & - & 1.00 & - & 0.33 & 1.08 & 0.29 \\
\hline $20: 5 n-3$ & 37.16 & 51.54 & - & 18.23 & 20.56 & 27.90 & 22.91 & 58.14 & 11.28 & 21.39 & 33.19 & 29.22 & 23.10 & 19.98 & 12.49 & 10.26 \\
\hline $22: 6 n-6$ & 7.82 & 12.14 & - & - & 3.15 & 4.32 & - & - & - & 3.55 & - & 2.09 & - & 0.53 & 1.04 & 0.96 \\
\hline
\end{tabular}

Results are reported as $\%$ of total fatty acids. $\mathrm{PC}=$ phosphatidylcholine; $\mathrm{PE}=$ phosphatidylethanolamin; $\mathrm{PG}=$ phosphatidylglycerol; $\mathrm{SQDG}=$ sulfoquinovosyldiacylglycerol; DGDG = digalactosyldiacylglycerol; $\mathrm{MGDG}=$ monogalactosyldiacylglycerol; TAG = triacylglycerol; $-=$ not detected; $n=2$.

important function of this lipid class in membranes of sea ice diatoms. Changes also occurred in fatty acid composition of each lipid class which has implications for the degree of lipid saturation and thus for membrane fluidity (Fig. 8, Table 3). Our data reveal that the proportion of polyunsaturated fatty acids under nitrogen limited growth increased in most of the lipid classes, except for dominant chloroplast related MGDG and triacylglycerol (TAG) where they decreased or remained constant.

\section{Discussion}

Sea ice diatoms appear to have sophisticated mechanisms for photosynthetic energy conversion under dynamic $N$-supply in order to regulate (i) underlying structural components which are dependent on proteins and $N$-containing molecules and (ii) the discrepancy between energy input and the potential to use this energy for growth. In plants, the most affected structures under $N$-limitation are photosystems within the thylakoid membranes. Under such conditions it is likely that lightharvesting-protein complexes and reaction centre proteins like D1/D2 (reaction center proteins of PS II) are only poorly assimilated (e.g. Falkowski et al., 1989) and consequently less concentrated in the thylakoid membrane. This loss of integral polar membrane compo- nents has consequences for membrane structure and thus lipid composition as well as the degree of fatty acid desaturation. Low light acclimated microalgae used here were characterized by large chloroplasts. Consequently, the most membrane systems were related to chloroplasts and particular thylakoid membranes (Forde and Steer, 1976) which explains the dominance of MGDG. Typical chloroplast related lipid classes for microalgae are MGDG, DGDG, SL, PG with minor amounts of PC and PI (Mendiola-Morgenthaler et al., 1985). Significant changes in concentration were probably the result of physiological reactions in order to sustain the optimal structure and function of chloroplast membranes even under sub-optimal conditions of nitrogen limitation at low temperature. The overall reduction of proteins was accompanied by an increase in membrane lipids which caused an increased lipid/ protein ratio also in thylakoid membranes (Block et al., 1983). This physiological acclimation may compensate structural changes of the thylakoid membrane because of reduced pigments and proteins within the membrane. Pigments and proteins are normally responsible for bilayer formation at unusually high concentrations of non-bilayerforming MGDG (Quinn and Williams, 1985; Murphy, 1984; Webb and Green, 1991). The precise role of non-bilayer lipids in membranes is still unclear. Early suggestions that they facilitate the sealing of proteins into membranes remain extremely plausible 
but detailed evidence is still missing. When less proteins and pigments are available, the thylakoid membrane has to be stabilized in a bilayer-state by increasing the concentrations of bilayer forming lipids such as DGDG and phospholipids. Hexagonal structures of MGDG would develop micelles, which destroy the thylakoid lipid bilayer (Williams, 1998). Highly unsaturated PG is normally a functional effector for charge separation at the D1/D2-heterodimer, electron flow and a membrane anchor for the D1-core peptide (Kruse and Schmidt, 1995; Duchene et al., 2000). Either the assembly of new D1 protein into active PS II reaction centers or the processing of the pre-D1 protein appears to depend on the degree of unsaturation of the thylakoid lipids, particularly at low temperatures (Murata and Wada, 1995; Nishida and Murata, 1996). Increasing concentrations of PG PUFAs under $N$-limitation was probably an instrument for improving the incorporation of D1 proteins into the thylakoid membrane. Additionally, the PUFA content (20:5 n-3) of most phospholipid classes increased under $N$-limitation. Decreasing MGDG PUFAs like 20:5 n-3, during $N$-limitation, is probably related to decreasing chl $a$, because there is a strong association between both substances (e.g. Cohen et al., 1988) $N$-limitation would disrupt the entire chloroplast membranes and thus photosynthesis if the cell was not able to compensate the reduction of pigments and proteins inside the thylakoid membrane. These regulating mechanisms are probably universal to establish membrane integrity and consequently active photosynthesis in sea ice diatoms or even other algae or higher plants.

The light energy which was absorbed per unit chl $a$ in nitrogen limited cells increased because of decreasing chl $a$ contents. The incoming energy is therefore concentrated in a few PS II reaction centres. The electron transport from PS II to triacylglycerols, the primary electron sink, is dependent on the amount of $\mathrm{Q}_{\mathrm{A}}$ and $\mathrm{Q}_{\mathrm{B}}$, their mobility through the membrane and the amount of redox-equivalents (NADPH) as electron acceptors. Fluorescence amplitudes indicated that the amount of bound $\mathrm{Q}_{\mathrm{B}}$ at $\mathrm{D} 1$ increased during $N$-limitation, but that the rate constants decreased. The binding site of D1 therefore does not seem to be negatively influenced by $N$-limitation so that only less $\mathrm{Q}_{\mathrm{B}}$ can be bound but the exchange of reduced against oxidized $\mathrm{Q}_{\mathrm{B}}$ and the mobility of $\mathrm{Q}_{\mathrm{B}}$ is more likely responsible for the reduced rate constants. One consequence of this reduced flow of electrons is a tailback of electrons within the transport chain, including $\mathrm{Q}_{\mathrm{A}}$. Under sufficient nitrogen availability these electrons are normally used for a reduction in nitrate. Here they are used more for intense carbon assimilation in the form of triacylglycerols.

Nevertheless, the PQ pool remained reduced, indicating an inbalance between electron generation and all processes that remove electrons such as reduced substances or enzymes, which require electrons for their reactions. This highly reduced state of the plastoquinone pool is probably the trigger for production of diatoxanthin and diadinoxanthin which protects the reaction centre from photoinhibition by exciton dissipation. The strongly reduced plastoquinone pool also inhibits de novo LHC (light harvesting complex) synthesis (Falkowski et al., 1989). Consequently, the response to nitrogen limitation is similar to the high light response (Kolber et al., 1988; Herzig and Falkowski, 1989).

\section{Experimental}

\subsection{Site and sampling}

Sea ice algal assemblages were collected in the Weddell Sea (Antarctica) during the RV 'Polarstern' expedition ANT XVI/3 from 18 March to 10 May 1999. Samples were taken from one first year sea ice floe of 37 $\mathrm{cm}$ thickness (station PS 53 177) at $70^{\circ} 02^{\prime} 04^{\prime \prime} \mathrm{S}$, $06^{\circ} 00^{\prime} 06^{\prime \prime} \mathrm{W}$ using a $9 \mathrm{~cm}$ ice auger. Only the bottom 5 $\mathrm{cm}$ of several ice cores, containing the highest density of algae, was used. The segments were placed into clean 5-1 polyethylene containers and returned to the ship where they were transferred into $0.2 \mu \mathrm{m}$ pre-filtered seawater (defined as sterile) with a final dilution of 4:1 (volume sea water:volume sea ice) at $0{ }^{\circ} \mathrm{C}$ to avoid osmotic stress during the melting procedure (Garrison and Buck, 1986). They were allowed to melt at $0{ }^{\circ} \mathrm{C}$ and a light intensity of approx. $7 \mu \mathrm{mol}$ photons $\mathrm{m}^{-2} \mathrm{~s}^{-1}$.

\subsection{Experimental set-up}

After melting (ca. $24 \mathrm{~h}$ ), the sedimented algae were drawn up by a sterile syringe and transferred into $10 \mathrm{ml}$ "petri" dishes of sterile F/2 medium (Guillard and Ryther, 1962). Representatives of the dominant diatom species: Fragilariopsis curta, Navicula gelida var.antarctica, Nitzschia medioconstricta were picked up by a glass pipette. These species were transferred into aerated 1-1 glass bottles containing F/2 medium. Illumination (cool white fluorescent tubes, Philips TL 33) was provided from above and the photon flux density within the bottles was adjusted to $15 \mu \mathrm{mol}$ photons $\mathrm{m}^{-2} \mathrm{~s}^{-1}$ and a light-dark cycle of 20:4 h. Growth of unialgal cultures with respect to irradiance was similar to that often observed under low temperature and light conditions (e.g. Fiala and Oriol, 1990). After 1 week, all the exponentially growing diatoms were transferred into 5-1 bottles for continuous cultures under the same light conditions used in the batch cultures. Antarctic sea water was enriched with $F / 2$ nutrients twice as high as recommended by Guillard and Ryther (1962) in order to avoid nutrient limitation. $\mathrm{F} / 2$ medium with a reduced nitrate concentration was used for nitrogen limited 
growth experiments. Nutrient concentrations were checked daily and immediately determined after sampling according to standard seawater procedures (Grasshoff et al., 1983). The pH of the cultures was kept constant at $8.00 \pm 0.15$ by bubbling air at a rate of $270-\mathrm{ml} \mathrm{min}^{-1}$. The airflow was used to vigorously mix the culture. Temperature was kept constant at $-1 \pm 0.5{ }^{\circ} \mathrm{C}$ by cooling the entire laboratory. Steady state cell concentrations were checked at $750 \mathrm{~nm}$ with a Shimadzu Photometer and microscopical analyses of species composition were carried out according to Utermöhl (1958). Under nutrient replete conditions, the maximal attained dilution rate for steady state growth was $0.55 \mathrm{day}^{-1}$ whereas steady state growth under nitrogen limitation was adjusted to $0.28 \mathrm{day}^{-1}$. The average photon flux densities for both experimental conditions was $15.0 \pm 5.0 \mu \mathrm{mol}$ photons $\mathrm{m}^{-2} \mathrm{~s}^{-1}$ with an optical density (OD) of $0.11 \pm 0.01$ at $0.55 \mathrm{day}^{-1}$ and an OD of $0.08 \pm 0.01$ at $0.28 \mathrm{day}^{-1}$. The algal composition at a growth rate of $0.55 \mathrm{day}^{-1}$ was $66 \pm 11 \%$ Navicula gelida var. antarctica, $20 \pm 7 \%$ F. curta and $14 \pm 9 \%$ N. medioconstricta after ca. 1 week under steady state cell concentrations. During nitrate deplete growth and a growth rate of $0.28 \mathrm{day}^{-1} N$. gelida var. antarctica contributed $61 \pm 8 \%, F$. curta $27 \pm 9 \%$ and $N$. medioconstricta $12 \pm 4 \%$ to the total community based on cell numbers.

\subsection{Bio-optics}

Pigment composition was determined by High Performance Liquid Chromatography (HPLC). Samples of $20 \mathrm{ml}$ were filtered through Whatmann $\mathrm{GF} / \mathrm{C}$ filters, which were placed in cryo vials and immediately frozen in liquid nitrogen. They were then stored at $-80{ }^{\circ} \mathrm{C}$ for about 4 months prior to pigment extraction in $100 \%$ DMF (dimethylformamide) and subsequent HPLC analysis. HPLC protocols followed Karsten and GarciaPichel (1996) with some modification. Pigments were separated using a Waters Associates HPLC system which includes a $600 \mathrm{MS}$ gradient module with system controller and a Model 996 photodiode array detector. Samples $(50 \mu \mathrm{l})$ were injected into a HPLC column by an autosampler (717 plus). The column was a stainless steel Merck LiChrospher RP 18 (5 $\mu$ m packing; $125 \times 4$ mm I.D.) behind a Merck RP 18 guard column $(4 \times 4$ $\mathrm{mm}$ I.D.), filled with the same material. Pigments were monitored at $436 \mathrm{~nm}$ and separated by a binary gradient system of helium-degassed solvents. The mobile phase of solvent A (distilled water) and solvent B (acetonitrile-methanol-tetrahydrofuran, 75:15:10 vol:vol) was regulated at a flow rate of $1.5 \mathrm{ml} \mathrm{min}^{-1}$ using the following program: $0-15 \mathrm{~min}$ for a linear increase from $15 \%$ solvent $A$ to $100 \%$ solvent $B$ and $15-24 \mathrm{~min}$ for $100 \%$ solvent $\mathrm{B}$. The individual pigments were identified by their absorption spectra in a mixture of solvent $A$ and solvent $B$ at the appropriate retention time. Their identification was evaluated against co-chromatography with commercially available standards (International Agency for ${ }^{14} \mathrm{C}$ Determination VKI). Pigments were quantified by peak area at $436 \mathrm{~nm}$ with reference to response signals obtained from the standards using the Waters 996 photodiode array detector and integrator.

Chl $a$ fluorescence measurements were conducted with a Dual-Modulation LED Kinetic Fluorometer (Trtilek et al., 1997). Fluorescence induction measurements were done on samples $(11.5 \pm 2.1 \mu \mathrm{g}$ total $\operatorname{chl} a)$ that had been dark adapted for $30 \mathrm{~min}$ in the presence of DCMU [3-(3,4-dichlorophenyl)-1,1-dimethylurea, $20 \mu \mathrm{mol} 1^{-1}$ final concentration]. Consequently DCMU induction kinetics reveal the potential maximum of photosynthetic performance and not in situ kinetics. Reoxidation kinetics of $\mathrm{Q}_{\mathrm{A}}$ were determined as soon as possible after sampling (90 s) and after $30 \mathrm{~min}$ in order to test the influence of dark adaptation on the amount of bound $\mathrm{Q}_{\mathrm{B}}$. When dark adapted DCMU containing cells are light-exposed, fluorescence will increase from a minimum level $F_{\mathrm{O}}\left(\mathrm{Q}_{\mathrm{A}}\right.$ fully oxidized, PS II reaction centres open) to a maximum level Fm $\left(Q_{A}\right.$ fully reduced, i.e. all PS II reaction centres closed). These cells displayed a fast fluorescence increase upon illumination because electron transport between the primary stable electron acceptor $\mathrm{Q}_{\mathrm{A}}$ and the secondary acceptor $\mathrm{Q}_{\mathrm{B}}$ was blocked. Normalized DCMU-induction curves were fitted to a set of equations (Trissl and Lavergne, 1995; Lavergne and Trissl, 1995). Any increase from $F_{\mathrm{o}}$ is termed variable fluorescence $\left[F_{\mathrm{v}}(\mathrm{q})\right]$ and can be described as

$F_{\mathrm{v}}(q)=\Phi_{\mathrm{f}}(q 0)-F_{\mathrm{o}}$

where $\Phi_{\mathrm{f}}(q 0)$ is the fluorescence yield which is defined as

$\Phi_{\mathrm{f}}(q 0)=F_{\mathrm{m}}-q_{(t)}\left(F_{\mathrm{m}}-F_{\mathrm{o}}(1+J)\right) / 1+J q_{(t)}$

where $J$ is a measure of the connectivity between PS II centres and is related to Joliot's connection parameter $p$ by

$J=p /(1-p)$

where $p$ was defined as the probability that an exciton hitting a closed reaction centre will be transmitted to an open reaction centre (Joliot and Joliot, 1964). The $q_{(t)}$ is calculated from the fraction of open centre at time $t_{-1}$ and the change in open centres in $\mathrm{dt}$

$q_{(t)}=q(t-1)+\mathrm{d} q$

where $\mathrm{d} q$ can be described as

$\mathrm{d} q=\sigma p_{(t-1)}{ }^{*}(1+J) /\left(1+J q_{(t-1)}\right)^{*} \mathrm{~d} t$ 
and $\sigma$ is a relative measure of the cross section of PS II. Photochemical quantum yield of PS II from fluorescence levels is expressed as (Schreiber et al., 1986; Genty et al., 1989)

$$
\Phi_{\mathrm{p}}(q)=F_{\mathrm{m}}-\Phi_{\mathrm{f}}(q 1) / F_{\mathrm{m}}
$$

Reoxidation kinetics of $\mathrm{Q}_{\mathrm{A}}$ were measured by decay of variable fluorescence back to the $F_{\mathrm{o}}$ state in absence of DCMU with decreasing resolution during $100 \mathrm{~s}$, starting $120 \mu \mathrm{s}$ after firing of six single turnover flashes to saturate all reaction centres. The decay kinetics reflects the re-oxidation of $\mathrm{Q}_{\mathrm{A}}$ by $\mathrm{Q}_{\mathrm{B}}$. Complete $\mathrm{Q}_{\mathrm{A}}$ reoxidation can be described by a triphasic exponential decay function for $F_{\mathrm{v}}$

$F_{\mathrm{v}}=A_{\mathrm{e}}^{-\mathrm{Ka}^{*} \mathrm{t}}+B_{\mathrm{e}}^{-\mathrm{Kb}^{*} \mathrm{t}}+C_{\mathrm{e}}^{-\mathrm{Kc}^{*} \mathrm{t}}+F_{\mathrm{o}}$

where $A, B$ and $C$ are the amplitudes and $K_{A}, K_{B}$ and $K_{C}$ the decay rate constants for the fast $(<10 \mathrm{~ms})$, middle $(10-50 \mathrm{~ms})$ and slow (>50 ms) phase, respectively. The fast phase is attributed to electron transport from $\mathrm{Q}_{\mathrm{A}}$ to $\mathrm{Q}_{\mathrm{B}}$ in centres that possess bound $\mathrm{Q}_{\mathrm{B}}$. The middle phase is thought to represent those centres that had no bound $\mathrm{Q}_{\mathrm{B}}$ before the flash. Thus this phase may indicate the kinetics of equilibration of $\mathrm{PQ}$ binding to the $\mathrm{Q}_{\mathrm{B}}$ site of the D1 protein. The third, very slow component seems to represent the decay of PS II centres that are unable to transmit electrons to the PQ pool. The slow $\mathrm{Q}_{\mathrm{A}}$ reoxidation apparent from this phase is thought to result from recombination between $\mathrm{Q}_{\mathrm{A}}$ and the water oxidation system in the $\mathrm{S}_{2}$ state.

$P$ vs $I$ curves were done on $10 \mathrm{ml}$ algal samples filled into $10 \mathrm{ml}$ transparent polycarbonate cuvettes lined up and illuminated by a slide projector. Photon flux density within the cuvettes was adjusted with neutral density filters, which covered the cuvette side in front of the slide projector. The photon flux density determined within filled cuvettes ranged between 0.5 and $395 \mu \mathrm{mol}$ photons $\mathrm{m}^{-2}$ $\mathrm{s}^{-1}$. The illumination time was $2 \mathrm{~h}$ at $-1{ }^{\circ} \mathrm{C}$ with regular stirring every $15 \mathrm{~min}$. The quantum yield was measured with a Dual-Modulation LED Kinetic Fluorometer (Trtilek et al., 1997). Fluorescence induction measurements were done on samples $(11.5 \pm 2.1 \mu \mathrm{g}$ total $\mathrm{chl} a)$ that had been dark adapted for $30 \mathrm{~min}$ in the presence of DCMU. $P$ vs $I$ parameters $\alpha, P_{\max }$, and Ik were determined by a fit according to Eilers and Peeters (1988).

\subsection{Biochemistry}

For particulate organic carbon (POC) and nitrogen $(\mathrm{PON})$, carbohydrate, protein and lipid analyses, samples of $40 \mathrm{ml}$ were filtered through precombusted Whatmann GF/C filters. Filters for POC/PON, carbohydrates and proteins were kept frozen at $-80{ }^{\circ} \mathrm{C}$ for further processing. The thawed filters for $\mathrm{POC} / \mathrm{PON}$ were dried $\left(12 \mathrm{~h}\right.$ at $\left.60{ }^{\circ} \mathrm{C}\right)$, transferred to pewter foil and combusted in oxygen enriched helium atmosphere in a Heraeus CHN-O-Rapid analyzer. Concentrations of carbohydrates were determined after Holland and Gabbott (1971) and proteins were determined after Smith et al. (1985) with a BCA Protein Assay Kit (Pierce, Rockford, IL 61105) which has serum albumin as standard. Filters for lipid analyses were immediately aerated with $\mathrm{N}_{2}$ after filtration and stored in dichlormethane:methanol (2:1, by vol.) at $-80{ }^{\circ} \mathrm{C}$ for further processing. Algal cells together with the filter were sonicated for $5 \mathrm{~min}$ with a stainless-steel probe and extracted in the storage solution (Folch et al., 1957). Lipid class composition was measured by quantitative thin-layer chromatography densitometry (HPTLC) as described by Olsen and Henderson (1989) with some modifications. Individual lipid classes were isolated on precoated HPTLC silica gel 60 plates $(20 \times 10 \mathrm{~cm}$, Merck, Darmstadt, Germany). Lipid standards for each lipid class were obtained from Sigma Chemical Pool, U.K. Lipid samples $(100 \mu \mathrm{l})$ were added with a Linomat $(\mathrm{Carmag}, \mathrm{CH})$ as a sharp line over nearly the full width $(8 \mathrm{~cm})$ of the plates. All developments were performed at room temperature in saturated standard chambers for $20 \times 10 \mathrm{~cm}$ HPTLC plates loaded with standards or samples. The first development ran to a distance of $12 \mathrm{~cm}$ from the origin using methyl acetate:isopropanol:chloroform: methanol: $0.25 \% \mathrm{KCl}(25: 25: 25: 10: 4$ by vol.) as the solvent system. After evaporation of the solvents at $110^{\circ} \mathrm{C}$ for $5 \mathrm{~min}$, the plates were dried under a stream of $\mathrm{N}_{2}$. Plates were then developed in hexane:diethyl ether:glacial acetic acid (70:30:2 by vol.) to $17 \mathrm{~cm}$ from the origin. Separated lipid classes or standards were detected by spraying the plates with $3 \% \mathrm{H}_{2} \mathrm{SO}_{4}$, followed by charring at $200{ }^{\circ} \mathrm{C}$ for $15 \mathrm{~min}$. Quantification was performed on a Carmag TLC scanner. Preparation of individual fatty acids (FAs) for each lipid class were conducted on parallel samples using $400 \mu \mathrm{l}$ instead of $100 \mu \mathrm{l}$ to ensure sufficient material for gas chromatography analyses. The separated lipid classes were directly scraped off after both developments using a standard plate with detected lipid classes for orientation. FAs were resuspended in $5 \mathrm{ml}$ dichlormethane:methanol (2:1 by vol.) and then separated from silica gel by centrifugation (2000 rpm for $5 \mathrm{~min}$ ). Thereafter FAs were transmethylated in methanol containing $2 \%$ sulphuric acid for $4 \mathrm{~h}$ at $80{ }^{\circ} \mathrm{C}$ to generate fatty acid methyl esters (FAME) which were extracted with hexane and analysed by gas liquid chromatography with a Carlo Erba gas chromatograph. FAs were identified with a standard mixture.

\section{Acknowledgements}

We are grateful to the crew of the RV Polarstern for their assistance during the expedition. We thank Gerhard 
Kattner and Martin Graeve for valuable discussions and for kind assistance with the lipids. Gerhard Dieckmann is thanked for reviewing an earlier version of the manuscript, and making suggestions for its improvement.

\section{References}

Allen, D.J., Ort, D.R., 2001. Impacts of chilling temperatures on photosynthesis in warm-climate plants. Trends in Plant Sci. 6 (1), 36-42.

Arrigo, K.R., Worthen, D.L., Lizotte, M.P., Dixon, P., Dieckmann, G., 1997. Primary production in Antarctic sea ice. Science 276, 394-397.

Block, M.A., Dorne, A.J., Joyard, J., Douch, R., 1983. Preparation and characterization of membrane fractions enriched in outer and inner envelope membranes from spinach chloroplasts. II Biochemical characterization. J. Biol. Chem. 258, 13281-13286.

Cohen, Z., Vonshak, A., Richmond, A., 1988. Effect of environmental conditions on fatty acid composition of the red alga Porphyridium cruetum: correlation to growth rate. J. Phycol. 24, 328-332.

Duchene, S., Smutny, J., Siegenthaler, P.A., 2000. The topology of phosphatidylglycerol populations is essential for sustaining photosynthetic electron flow activities in thylakoid membranes. Biochim. Biophys. Acta 1463, 115-120.

Eicken, H., 1992. The role of sea ice in structuring Antarctic ecosystems. Polar Biol. 12, 3-13.

Eilers, P.H., Peeters, J.C.H., 1988. A model for the relationship between light intensity and the rate of photosynthesis in phytoplankton. Ecol. Model. 42, 199-215.

Falkowski, P.G., Sukinek, A., Herzig, R., 1989. Nitrogen limitation in Isochrysis galbana (Haptophyceae). II. Relative abundance of chloroplast proteins. J. Phycol. 25, 471-478.

Fiala, M., Oriol, L., 1990. Light-temperature interactions on the growth of Antarctic diatoms. Polar Biol. 10, 629-636.

Folch, J., Lees, M., Sloane-Stanley, G.H., 1957. A simple method for the isolation and purification of total lipids from animal tissues. J. Biol. Chem. 226, 497-509.

Forde, J., Steer, M.W., 1976. The use of quantitative electron microscopy in the study of lipid composition of membranes. J. Exp. Bot. 27, 1137-1141.

Garrison, D.L., Buck, K.R., 1986. Organism losses during ice melting: a serious bias in sea ice community studies. Polar Biol. 6, 237-239.

Genty, B., Briantais, J.M., Baker, N.R., 1989. The relationship between the quantum yield ofphotosynthetic electron transport and quenching of chlorophyll fluorescence. Biochim. Biophys. Acta 90, 87-92.

Guillard, R.R., Ryther, J.H., 1962. Studies of marine plankton diatoms. I. Cyclotella nana (Husted) and Detonula confervacea (Cleve). Can. J. Microbiol. 8, 229-239.

Grasshoff, K., Ehrhard, M., Kremling, K., 1983. Methods of Sea Water Analyses, 2nd ed. Verlag Chemie, Weinheim.

Herzig, R., Falkowski, P.G., 1989. Nitrogen limitation in Isochrysis galbana (Haptophyceae) I. Photosynthetic energy conversion and growth efficiencies. J. Phycol. 25, 462-471.

Holland, D.L., Gabbott, P.A., 1971. A micro-analytical scheme for determination of proteins, carbohydrates, lipid and RNA levels in marine invertebrate larvae. J. Mar. Biol. Assoc. UK 51, 659-668.

Hutchinson, G.E., 1961. The paradox of the plankton. Am. Nat. 95, 135-137.

Joliot, P., Joliot, A., 1964. Études cinétique de la réaction photochimique libérant l'oxygene au cours de la photosynthese. C. R. Acad. Sci. Paris 258, 4622-4625.

Karsten, U., Garcia-Pichel, F., 1996. Carotenoids and mycosporinelike amino acid compounds in members of the genus Microcoleus (cyanobacteria): a chemosystematic study. System Appl. Microbiol. 19, 285-294.

Kirst, G.O., Wiencke, C., 1995. Ecophysiology of polar algae. J. Phycol. 31, 181-199.
Kolber, Z., Zehr, J., Falkowski, P.G., 1988. Effects of growth irradiance and nitrogen limitation on photosynthetic energy conversion in photosystem II. Plant Physiol. 88, 923-929.

Kroon, B.M.A., 1994. Variability of photosystem II quantum yield and related processes in Chlorella pyrenoidosa (Chlorophyta) acclimated to an oscillating light regime simulating a mixed photic zone. J. Phycol. 30, 841-852.

Kroon, B.M.A., Prézelin, B.B., 1995. Temperature dependency of fluorescence decay parameters in an Antarctic isolate of the diatom Thalassiosira sp. Antarct. J. US. 159-160.

Kruse, O., Schmidt, G.H., 1995. The role of phosphatidylglycerol as a functional effector and membrane anchor of the D1-core peptide from photosystem II-particles of the cyanobacterium Oscillatoria chalybea. Z. Naturforsch. 50c, 380-390.

Lavergne, J., Trissl, H.W., 1995. Theory of fluorescence induction in photosystem II: derivation of analytical expressions in a model including exciton-radical-pair equilibrium and restricted energy transfer between photosynthetic units. Biophys. J. 88, 2474 2492.

McMinn, A., Skerratt, J., Trull, T., Ashworth, C., Lizotte, M., 1999. Nutrient stress gradient in the bottom $5 \mathrm{~cm}$ of fast ice, McMurdo Sound, Antarctica. Polar Biol. 21, 220-227.

Mendiola-Morgenthaler, L., Eichenberger, W., Boschetti, A., 1985. Isolation of chloroplast envelopes from Chlamydomonas. Lipid and polypeptide composition. Plant Sci. 41, 97-104.

Murata, N., Wada, H., 1995. Acyl-lipid desaturases and their importance in the tolerance and acclimatization to cold of cyanobacteria. Biochem. J. 308, 1-8.

Murphy, D., 1984. Structural properties and molecular organization of the acyl lipids of photosynthetic membranes. In: Staehelin, L.A., Arntzen, C.J. (Eds.), Encyclopedia of Plant Physiology. Photosynthesis III: Photosynthetic Membranes and Light-Harvesting Systems, Vol. 19. Springer-Verlag, Berlin, pp. 713-725.

Nishida, I., Murata, N., 1996. Chilling sensitivity in plants and cyanobacteria: the crucial contribution of membrane lipids. Annu. Rev. Plant. Physiol. Plant. Mol. Biol. 47, 541-568.

Olsen, R.E., Henderson, R.J., 1989. The rapid analysis of neutral and polar marine lipids using double-developmant HPTLC and scanning densitometry. J. Exp. Mar. Biol. Ecol. 129, 189-197.

Pohl, F., Zurheide, 1979. Fatty acids and lipids of marine algae and the control of their biosynthesis by environmental factors. In: Hoppe, H.A., Levring, T., Tanaka, Y. (Eds.), Marine Algae in Pharmaceutical Science. Walter de Gruyter, Berlin, pp. 473-523.

Quinn, P.J., Williams, W.P., 1985. Environmentally induced changes in chloroplast membranes and their effects on photosynthetic function. In: Barber, J. (Ed.), Topics in Photosynthesis, Vol. 6. Elsevier, Amsterdam, pp. 1-47.

Routaboul, J.M., Fischer, S.F., Browse, J., 2000. Trienoic fatty acids are required to maintain chloroplast function at low temperatures. Plant Physiol. 124, 1697-1705.

Schreiber, U., Schliwa, U., Bilger, W., 1986. Continuous recording of photochemical and non-photochemical chlorophyll fluorescence quenching with a new type of modulation fluorometer. Photosynth. Res. 10, 51-62.

Shifrin, N.S., Chisholm, S.W., 1981. Phytoplankton lipids: interspecific differences and effects of nitrate, silicate and light-dark cycles. J. Phycol. 17, 374-384.

Siegenthaler, P.A., Murata, N., 1998. Lipids in Photosynthesis: Structure, Function and Genetics, Advances in Photosynthesis, Vol. 6. Kluwer Academic Publishers, Dordrecht.

Smith, P.K., Krohn, R.I., Hermanson, G.T., Mallia, A.K., Gartner, F.H., Provenzano, M.D, Fujimoto, E.K., Goecke, N.M., Olson, B.J., Klenk, D.C., 1985. Measurement of protein using bicinchoninic acid. Anal. Biochem. 150, 76-85.

Taguchi, S., Smith, R.E.H., 1997. Effects of nitrogen and silicate enrichment on photosynthate allocation by ice algae from Resolute Passage, Canadian Arctic. J. Mar. Syst. 11, 53-61. 
Thomashow, M.F., 1998. Role of cold-responsive gene in plant freezing tolerance. Plant Physiol. 118, 1-7.

Tillmann, U., Baumann, M.E.M., Aletsee, L., 1989. Distribution of carbon among photosynthetic end products in the bloom-forming diatom Thalassiosira antarctica COMBER. Polar Biol. 10, 231-238.

Trissl, H.W., Lavergne, J., 1995. Fluorescence induction from photosystem II: analytical equations for the yields of photochemistry and fluorescence derived from analysis of a model including excitonradical pair equilibrium and restricted energy transfer between units. Aust. J. Plant Physiol. 22, 183-193.

Trtilek, M., Kramer, D.M., Koblizek, M., Nedbal, L., 1997. Dualmodulation LED kinetic fluorometer. J. Lumin. 72-74, 597-599.
Utermöhl, H., 1958. Zur Vervollkommnung der quantitativen Phytoplankton-Methodik. Mitt. Int. Ver. Theor. Angew. Limnol. 9, $1-38$.

Webb, M.S., Green, B.R., 1991. Biochemical and biophysical properties of thylakoid acyl lipids. Biochim. Biophys. Acta 1060, 133-158.

Weissenberger, J., Dieckmann, G., Gradinger, R., Spindler, S., 1992. Sea ice: a case technique to examine and analyze brine pockets and channel structure. Limnol. Oceanogr. 37 (1), 179-183.

Williams, W.P., 1998. The physical properties of thylakoid membrane lipids and their relation to photosynthesis. In: Siegenthaler, P.A., Murata, N. (Eds.), Lipids in Photosynthesis: Structure, Function and Genetics, Vol. 6. Kluwer Academic, Dordrecht, pp. 21-52. 